\title{
Factors for Low Uptake of Antiretroviral Therapy Among HIV Pregnant Women in Mbeya City Council, Tanzania
}

\author{
Lawrencia Dominick Mushi
}

Mzumbe University, Tanzania

Eileen A Mhando

Mbeya Zonal Referral Hospital, Tanzania

Received: Feb. 11, 2019 Accepted: Mar. 1, 2019 Online published: Mar. 28, 2019

doi:10.5296/jpag.v9i1.14337

URL: https://doi.org/10.5296/jpag.v9i1.14337

\begin{abstract}
UNAIDS aimed to reach $90 \%$ antiretroviral therapy uptake among people living with HIV by 2015. Despite free provision of antiretroviral therapy to pregnant women living with HIV, the uptake remains low. This study describes views of pregnant women about low uptake of antiretroviral therapy among pregnant women living with HIV in Mbeya City Council.

The study used a descriptive cross-sectional design and applied mixed research approaches. 44 pregnant women on antiretroviral therapy and 12 health providers were conveniently selected. Four key informants were purposively selected. In-depth interviews with pregnant women and key informants; exit interviews with pregnant women; and observation of health providers were conducted. Audio tape recording from in-depth interviews was transcribed into Swahili to English. Social ecological framework was used in data coding based on individual, social and health service aspects then analysed using Atlas. ti 7. Quantitative data was analyzed in Excel spreadsheet, and presented using tables.

The findings from interviews and observations showed that the main individual factors (like treatment-related side effects and religious faith); social factors (like traditional medicine and lack of partner/husband support) and health service factors (like long waiting time and discrepancy in information given to clients during adherence counseling on antiretroviral therapy) were more likely to be associated with low uptake of antiretroviral therapy.

This study indicates that various factors at individual, social and health service levels were more likely to cause low uptake of ART. Reasons for discrepant information during
\end{abstract}


counseling by providers remain a question which needs further research.

Keywords: antiretroviral therapy, low ART uptake, HIV and AIDS, Tanzania

\section{Introduction}

Globally, 36.7 million people, including 1.8 million children, were living with HIV in 2015, with 1.1 million AIDS-related deaths. The burden of HIV has been greater in sub-Saharan Africa, which has approximately $69 \%$ of all HIV infections (UNAIDS, 2016). Mother-to-child transmission (MTCT) of HIV is a major route of HIV transmission among children. The risk of MTCT can range from $20 \%$ to $45 \%$ if no interventions are undertaken, and can be reduced to below 5\% if specific interventions are undertaken (WHO, 2010). Provision of antiretroviral therapy (ART) to pregnant women living with HIV reduces the risk of MTCT (UNAIDS, 2012). This intervention was implemented under the Prevention of Mother-to-Child Transmission (PMTCT) programme, which was initiated in Tanzania in 2000 to respond to the HIV epidemic with the ambitious goal of elimination of MTCT of HIV. One of the programme's objectives was to increase the percentage of pregnant women living with HIV who receive ART in order to reach the goal of $90 \%$ by 2015 (UNAIDS, 2016).

In guiding this implementation, the World Health Organisation (WHO) has developed various PMTCT guidelines at times to spearhead the efforts of preventing HIV infections among the children which adopted by different countries over time in Sub-Saharan Africa (WHO, 2013). Tanzania is implementing the WHO consolidated treatment guideline published in 2013 to accelerate the achievement of elimination of new HIV infection in children, and keep their mothers alive and healthy. The guideline recommended early initiation of Antiretroviral Therapy (ART) for life to all pregnant and breastfeeding women living with HIV soon after diagnosis, regardless of clinical eligibility, and be initiated in Reproductive and Child Health (RCH) clinics (WHO, 2013; WHO, 2015; NACP, 2011; MOHCDGEC, 2013).

Mbeya region was among the first six regions in Tanzania with the highest prevalence of HIV (9.0 per cent) (THMIS, 2012) to implement this guideline (MOHCDGEC, 2013), and Mbeya city being one of the council in Mbeya region has experienced high HIV prevalence (10.2 per cent) (COP, 2016). Various efforts have been done to eliminate MTCT included training of providers to implement guideline (WHO, 2015; NACP, 2011, DHIS, 2015). Despite free provision of ART in PMTCT clinics, still the uptake of ART remains low (75 percent) in Tanzania and (70 per cent) in Mbeya city (MoHCDGEC, 2016; DHIS, 2015) compared to the anticipated world and national target of $90 \%$ by 2015 (UNAIDS, 2013). Factors for low uptake of ART in Mbeya City Council are unknown. This led the need to conduct the study to describe views on low uptake of ART among pregnant women living with HIV in Mbeya City Council.

\section{Methods}

\subsection{Study Design}

The study used descriptive cross-sectional design and applied both qualitative and quantitative research approaches. It was conducted in Mbeya city one of the seven councils in 
Mbeya region. Based on 2012 population and housing census Mbeya has 385,279 inhabitants with population growth rate of 4 per cent (Census projection, 2016). The area was chosen because of high prevalence of HIV in the region, and it was among the councils in the first six pilot regions to implement the new consolidated PMTCT guideline published by World Health Organization in 2013.

\subsection{Study Subjects and Sampling}

This study was conducted between March and May 2017 involved a total of 60 respondents. Convenient selection of fourty-four pregnant women living with HIV was done including 38 who were continued with ART and only 6 were stopped ART and traced as lost to follow up (LTFU) were obtained in this study. This is because we did not have easy access to pregnant women who stopped ART and traced as LTFU. These respondents were selected because they are actual service users with experience in ART. Pregnant women were included if they were registered in PMTCT programme in January 2014 to December 2016 with more than one visits to PMTCT clinic. Exclusion criteria included pregnant women who were registered before January 2014 and after December 2016 and those with first visit to PMTCT clinics.

We also purposely selected 4 key informants who were in-charges in PMTCT clinics and 12 health care providers selected because of their wide knowledge in caring pregnant women living with HIV. Health providers and key informants were included if they worked in PMTCT clinics and were willing to participate in the study. Exclusion criteria included health providers who were not working in PMTCT clinics. Informed consent was obtained before conducting interviews and observations.

\subsection{Measurements}

The study examined three categories of variables (individual, social and health service factors) to understand on how they contribute to low uptake of ART. In this study the low uptake is defined as number of pregnant women not using ART for continuous 3 or more months at any time after initiation. The study adapted social ecological framework by Roura et al, (2009) to address these factors how they contribute to low uptake of ART among pregnant women living with HIV in PMTCT programme. A series of questions were asked to explore factors for low uptake of ART. At individual level the In-depth interview guide was used to collect information from pregnant women. The information on ART were measured with a series of questions where pregnant women described their experience in taking ART for PMTCT and measured whether continued, or had history of stopping ART (LTFU), and why they stopped ART. In this study (the pregnant woman was considered as LTFU if was started ART and then discontinued taking ART for previous continuous 3 or more months and traced).

In the social factors, In-depth interview guide was used to collect information from key informants where series of questions were asked for them to describe their views on various circumstances subjected pregnant women to discontinue ART. Also In-depth interview guide was used to collect social information from pregnant women who were asked to describe their views on relationship with family and community members and whether they received support or not. 
In the health service factors, the observation checklist was used to obtain information from health care providers. The providers' skills were observed and measured by a set of items of counseling session adopted from International Training and Education Centre on HIV (I-TECH) and analysed whether the provider were performed or not performed the skill required, similarly. Exit interview guide contained both closed and open- ended questions were used to collect information on health service factors from pregnant women after receiving health services whereby satisfaction of pregnant women on health services were measured by a set of likert scales questions adapted from I-TECH where pregnant women ranked for their satisfaction in waiting time for service, privacy in receiving service, materials given to educate them and interaction with health care providers during services and analysed whether the patient satisfied or not satisfied with services.

In-depth and exit interview guides were developed and translated from English to Kiswahili to cater for native Swahili speakers. The observation checklist format adapted from I-TECH was modified. We pilot-tested the interview guides with pregnant women at Ituha dispensary where some gaps identified and corrections were made improve the instruments. The main researcher conducted in-depth interview in office settings during working hours in working days and exit interview at the main entrance of $\mathrm{RCH}$ clinics. The interview typically lasted for 15 minutes.

\subsection{Data Analysis}

All interviews were transcribed and imported into Atlas.ti 7 software for analysis based on social-ecological framework as initial coding guide by grouping of codes to find out re-emerging patterns and themes. The non-quantifiable data and open ended questions subjected to content analysis and interpretation, and open-ended responses organized under the relevant subheadings to facilitate comprehension. The references of quotes from respondents were used to illustrate the points so as to make sense of findings. Quantitative data was entered in Microsoft Excel spreadsheet, checked for accuracy and completeness then analyzed and presented using tables.

\subsection{Ethical Consideration}

We obtained clearance from both Mzumbe University and Mbeya regional administrative secretary's office. Informed consent was obtained prior conducting the study. We maintained privacy during data collection process and ensured confidentiality of information provided by study participants. Information obtained was used only for the intended objective of the study.

\section{Results}

\subsection{Demographics}

The study enrolled a total of sixty respondents, including forty-four pregnant women living with HIV (Table 1). Out of forty-four, thirty nine were aged between twenty five to thirty five years of age, while three were above thirty five years and two respondents were between eighteen to twenty four years. Ten pregnant women were not married, twenty-eight were married, three were divorced and three widowed. Among them two did not attend school, 
thirty-two attended primary school and ten reached secondary schools. However, they all stayed far away from the health facility where twelve of them could spend an hour while thirty-two could spend more than one hour to the health facility. Thirty-five were Christians and nine were Muslims. Six pregnant women aged below thirty years with the second pregnancy where four of them stopped ART for the past three months while two of them stopped for the past nine months and the rest thirty eight pregnant women were continuing with ART.

Table 1. Sociodemographic characteristics of pregnant women living with HIV in Mbeya City council, Tanzania, 2016

\begin{tabular}{|c|c|c|}
\hline \multirow[b]{2}{*}{ Characteristics } & \multicolumn{2}{|c|}{$\begin{array}{c}\text { Total } \\
(\mathrm{N}=44)\end{array}$} \\
\hline & $\mathrm{N}$ & $(\%)$ \\
\hline \multicolumn{3}{|l|}{ Age (years) } \\
\hline $18-24$ & 2 & 4.5 \\
\hline $25-35$ & 39 & 88.6 \\
\hline Above 35 & 3 & 6.8 \\
\hline \multicolumn{3}{|l|}{ Education completed } \\
\hline Primary & 32 & 72.7 \\
\hline Secondary & 10 & 22.7 \\
\hline Did not attend school & 2 & 4.5 \\
\hline \multicolumn{3}{|l|}{ Religion } \\
\hline Christian & 35 & 79.5 \\
\hline Muslim & 9 & 20.5 \\
\hline Others & 0 & 0 \\
\hline \multicolumn{3}{|l|}{ Marital Status } \\
\hline Married & 28 & 63.6 \\
\hline Not married & 10 & 22.7 \\
\hline Widowed & 3 & 6.8 \\
\hline Divorced & 3 & 6.8 \\
\hline \multicolumn{3}{|l|}{ Distance to the facility } \\
\hline 1 hour & 12 & 27.3 \\
\hline More than 1 hour & 32 & 72.7 \\
\hline Clients Stopped ART & $\begin{array}{c}\text { Total } \\
(\mathrm{N}=6)\end{array}$ & \\
\hline \multicolumn{3}{|l|}{ Duration stopped ART } \\
\hline Past three months & 4 & 66.7 \\
\hline Past nine months & 2 & 33.3 \\
\hline
\end{tabular}

\subsection{Individual Level}

We explored individual factors and how they contributed to low uptake of ART. The results of twenty pregnant women (three who were LTFU, and seventeen who continued with ART) show that $(66.6 \%)$ said treatment related side effects of the medicine (ART) that included; vomiting, tiredness and body weakness were mentioned to stop patients from treatment (Table 2) One of pregnant women said:

"I was using the medicine (ART), to be sincere; it was causing me big problems. I used to be angry always and could not speak gently or do anything, sometime I experienced headache and fatigue, but after stopping the medicine, I feel better than going back to use the medicine" 
The results of five respondents (16.6\%) show that beliefs in God played role in stopping ART among pregnant women living with HIV. A respondent who was born again said:

“... I have decided to stop using the medicine "ART”, because, I have decided to handle all my life to Jesus; therefore Jesus alone is my healer, going back to medicine, I will not manage because I have decided to surrender my life to Jesus"

In addition, the results show that experiencing regaining physical health was mentioned by five $(16.6 \%)$ respondents to affect ART use. One respondent said:

"I decline the advice to continue use the medicines "ART" after seeing that I have never being in fever to the extent of being hospitalized that is why, I saw no need of continuing using them". Likewise, Views of seven respondents showed that being tired with treatment may reduce morale of taking medication.

Table 2. Individual factors contributing to low uptake of ART

\begin{tabular}{|c|c|c|c|}
\hline $\begin{array}{l}\text { Level of } \\
\text { factors }\end{array}$ & Contributing factor & Total $\mathrm{No}=30$ & $\%$ \\
\hline \multirow{3}{*}{$\begin{array}{l}\text { Individual } \\
\text { level }\end{array}$} & $\begin{array}{l}\text { Treatment related side } \\
\text { effects }\end{array}$ & 20 & 66.6 \\
\hline & Faith believes in God & 5 & 16.6 \\
\hline & Regaining physical health & 5 & 16.6 \\
\hline
\end{tabular}

\subsection{Social Level}

The findings show that out of thirty respondents, twenty six $(86.6 \%)$ respondents indicated that lack of support from husband subjected pregnant woman to stop ART (Table 3). One respondent said:

"When you get support from the relatives and community you feel like not having problem. But when you see that I have problem and people are stigmatizing, you find as if you belong to another world and stop medicine declaring that better to die".

The results from views of two key informants show that beliefs on witchcraft and relying on traditional medicine and faith healing played role in-patient to stop ART. One key informant said:

"According to our society here, people believes that if a pregnant woman is infected with HIV it is suspected to be witched so they prefer to go to the witch doctor for their treatment" Similarly, family obligations among pregnant women living with HIV were mentioned by two key informants to stop patient from ART.

One key informant said:

"Male partners in this area tends to go away from their homes to find means of earning money, so they left their wives at home to care for families, which sometimes found themselves too occupied with family obligations and lacks time to go to the health facility to collect medicine and finally they stop the treatment" 


\section{Macrothink}

Table 3. Social factors contributing to low uptake of ART

\begin{tabular}{|c|c|c|c|}
\hline $\begin{array}{l}\text { Level of } \\
\text { factors }\end{array}$ & Contributing factor & Total $\mathrm{No}=30$ & $\%$ \\
\hline \multirow{3}{*}{ Social level } & $\begin{array}{l}\text { Lack of partner/husband } \\
\text { support }\end{array}$ & 26 & 86.6 \\
\hline & $\begin{array}{l}\text { Beliefs of traditional } \\
\text { healing }\end{array}$ & 2 & 6.6 \\
\hline & Family obligations & 2 & 6.6 \\
\hline
\end{tabular}

\subsection{Health Service Level}

The eighteen pregnant women in exit interview all were responded to the questions of waiting time, privacy, materials given to educate them and interaction with health care workers where the results showed that, eleven respondents $(61.1 \%)$ were satisfied with waiting time for the service while seven (38.9) were not satisfied, fifteen respondents $(83.3 \%)$ were satisfied with privacy during service provision, while three $(16.7 \%)$ were not satisfied, fifteen respondents $(83.3 \%)$ were satisfied with materials provided to educate them while three $(16.7 \%)$ were not satisfied, and all eighteen respondents $(100 \%)$ were satisfied with interaction with health care workers (Table 4).

Table 4. Level of health services satisfaction among 18 respondents in PMTCT clinics

\begin{tabular}{|c|c|c|c|c|}
\hline \multirow[b]{2}{*}{$\begin{array}{l}\text { Factors in service } \\
\text { provision }\end{array}$} & \multicolumn{2}{|l|}{ Not satisfied } & \multicolumn{2}{|l|}{ Satisfied } \\
\hline & $\begin{array}{l}\text { Number of } \\
\text { respondents }\end{array}$ & $\%$ & $\begin{array}{c}\text { Number of } \\
\text { respondent } \\
\text { s }\end{array}$ & $\%$ \\
\hline Waiting time & 7 & 38.9 & 11 & 61.1 \\
\hline $\begin{array}{l}\text { Privacy/pace for } \\
\text { consultation }\end{array}$ & 3 & 16.7 & 15 & 83.3 \\
\hline $\begin{array}{l}\text { Information/education } \\
\text { materials }\end{array}$ & 3 & 16.7 & 15 & 83.3 \\
\hline $\begin{array}{l}\text { Interaction with health } \\
\text { care workers }\end{array}$ & 0 & 0 & 18 & 100 \\
\hline
\end{tabular}

Source: Field Researcher data; format adopted from International Training and Education Centre on HIV (I-TECH).

Regarding service provision, there were twelve service providers assessed through observation of skills in ART adherence counseling. The findings showed that nine providers manage to review treatment history of the patients about side effects while three providers did not. Ten providers managed to discuss with patients on the latest laboratory tests while two providers did not. Ten providers managed to assess the knowledge of medications among patients, including the patient understanding of drug resistance and implications while two providers did not. Nine providers reviewed with patients the possible barriers to adherence (such as stigma, support system, work, living situation, travel to clinic to pick up medication, side 


\section{Macrothink}

Journal of Public Administration and Governance

ISSN 2161-7104

2019, Vol. 9, No. 1

effect, depression and counseling of patients to identify strategies to overcome identified barriers) while three providers did not. However, all twelve health care providers managed to schedule next appointment and discussed what should prompt an earlier visit with the patient (Table 5).

Table 5. Summary findings of provider's skill performance in adherence counseling

\begin{tabular}{|c|c|c|c|c|c|}
\hline S/no & Skills required in ART adherence counseling & \multirow{2}{*}{\multicolumn{2}{|c|}{$\begin{array}{l}\text { Number of } \\
\text { providers } \\
\text { performed the } \\
\text { required skill }\end{array}$}} & \multirow{2}{*}{\multicolumn{2}{|c|}{$\begin{array}{l}\text { Number of } \\
\text { providers did } \\
\text { not perform } \\
\text { the required } \\
\text { skill }\end{array}$}} \\
\hline A & Review treatment history, including: & & & & \\
\hline & & No. & $\%$ & No. & $\%$ \\
\hline 1 & Current regime & 12 & 100 & 0 & 0 \\
\hline 2 & Previous medication & 12 & 100 & 0 & 0 \\
\hline 3 & Side effects & 9 & 75 & 3 & 25 \\
\hline 4 & Other treatments & 12 & 100 & 0 & 0 \\
\hline B & $\begin{array}{l}\text { Discuss current health status with patient, } \\
\text { include: }\end{array}$ & & & & \\
\hline 5 & Overall health and current problem & 11 & 91.7 & 1 & 8.3 \\
\hline 6 & Latest Laboratory tests (including CD4 count) & 10 & 83.3 & 2 & 16.7 \\
\hline 7 & Goals for health & 11 & 91.7 & 1 & 8.3 \\
\hline $\mathbf{C}$ & $\begin{array}{l}\text { Assess patient's medication knowledge, } \\
\text { behaviour and attitude, including }\end{array}$ & & & & \\
\hline 8 & Knowledge of HIV medications & 10 & 83.3 & 2 & 16.7 \\
\hline 9 & Understanding of resistance and implications & 8 & 66.7 & 4 & 33.3 \\
\hline 10 & Criteria for evaluation medications & 12 & 100 & 0 & 0 \\
\hline 11 & Attitudes about taking medication & 9 & 75 & 3 & 25 \\
\hline $\mathrm{D}$ & $\begin{array}{l}\text { Review patient's family's living situation, } \\
\text { including }\end{array}$ & & & & \\
\hline 12 & Eating patterns & 12 & 100 & 0 & 0 \\
\hline 13 & Daily activities: work, travel schedule & 11 & 91.7 & 1 & 8.3 \\
\hline 14 & Access to health facility & 10 & 83.3 & 2 & 16.7 \\
\hline 15 & $\begin{array}{l}\text { Special factors: disclosure of HIV diagnosis, } \\
\text { medication storage issues }\end{array}$ & 12 & 100 & 0 & 0 \\
\hline $\mathrm{E}$ & $\begin{array}{l}\text { Describes proposed medication regimen, } \\
\text { including }\end{array}$ & & & & \\
\hline 16 & Medicine names & 12 & 100 & 0 & 0 \\
\hline 17 & Dosing & 12 & 100 & 0 & 0 \\
\hline 18 & Food requirement & 11 & 91.7 & 1 & 8.3 \\
\hline 19 & Special instructions/how to give & 10 & 83.3 & 2 & 16.7 \\
\hline 20 & Side effects & 12 & 100 & 0 & 0 \\
\hline 21 & Storage issue & 10 & 83.3 & 2 & 16.7 \\
\hline
\end{tabular}




\begin{tabular}{|c|c|c|c|c|c|}
\hline $\mathbf{F}$ & Assess patient's readiness for regimen & & & & \\
\hline 22 & Review possible drug interactions & 8 & 66.7 & 4 & 33.3 \\
\hline 23 & $\begin{array}{l}\text { Review with patient possible barriers to } \\
\text { adherence (stigma, support system, work, living } \\
\text { situation, travel to clinic to pick up medication, } \\
\text { side effects, depression, etc) }\end{array}$ & 9 & 75 & 2 & 25 \\
\hline 24 & $\begin{array}{l}\text { Assist patient to identify possible barriers for her } \\
\text { adherence }\end{array}$ & 7 & 58.3 & 5 & 41.7 \\
\hline 25 & $\begin{array}{l}\text { Counsels patient to identify strategies to } \\
\text { overcome identified barriers }\end{array}$ & 6 & 50 & 6 & 50 \\
\hline $\mathbf{G}$ & Make plan for follow up & & & & \\
\hline 26 & $\begin{array}{l}\text { Schedule next appointment, discuss what should } \\
\text { prompt an earlier visit }\end{array}$ & 12 & 100 & 0 & 0 \\
\hline $\mathbf{H}$ & $\begin{array}{l}\text { Provides closure to adherence counselling } \\
\text { session }\end{array}$ & & & & \\
\hline 27 & $\begin{array}{l}\text { Ask patient to describe her ARV regimen, how to } \\
\text { get refills, what to do if experiences side effects, } \\
\text { when is next appointment, how to take } \\
\text { medications etc. }\end{array}$ & 9 & 75 & 3 & 25 \\
\hline
\end{tabular}

Source: Evaluator field data: The modified framework adopted from International Training and Education Center on HIV (I-TECH)

\section{Discussion}

Our study which described the low uptake of ART among pregnant women in health facilities of Mbeya city council revealed that individual, social and service factors such as; belief in God where patients received prayer as God's power to cure HIV subjected them to stop ART, treatment related side effects where respondents felt discomfort and reduced their urge to continue with ART and shifted to traditional medicine, regaining physical health when patients never experienced sickness, believed to be cured from HIV infection hence stopped ART. Similar findings reported in Zambia (Musheke et al, 2012) where respondents narrated how being "born again' and their "personal relationship" with God advised them to stop ART. Musheke et al, (2012) noted that ART related side effects interfered with patient health, comfort and daily activities hence reduced urge to ART. Contrary to this study, (Roura et al, 2009) found different views in the study done in Arusha, that patient stopped ART completely when they didn't experience physical healing.

Socially, aspects such as lack of support from husbands, witchcrafts and family obligations handled to women by male partners when they travel away were viewed as an obstacle for pregnant women to go clinic for their medication. Similar findings (Kim, 2016 and Gourlay, 2013) reported that lack of support from husbands became an obstacle for women to continue with ART soon after disclosed their HIV status. In the study done in Arusha (Roura et al, 2009), witchcraft believed to cause HIV and be cured through traditional medicine.

Service related aspects were; long waiting time claimed to be caused by shortage of staff, 
delay in starting services due to interactions with meetings, visitors, and too much explanation of providers during counseling hence patients conceived fear to be seen by others and be stigmatized. Studies done in Kenya, Zambia and Tanzania respectively (Hodgson, 2014, Musheke et al., 2012, Roura et al, 2009 and Munro et al. 2007) reported similar findings where long waiting time became a barrier among women to attend ART clinic for fear of being seen by others which could increase possibilities of being stigmatized.

Another aspect was lack of privacy during service provision where respondents claimed of overcrowding, small space at waiting places and rooms for services where sometimes more than one client entered the room to receive services created fear of being discovered by others. Furthermore, failure to provide reading materials for ART to patients subjected them to miss some information regarding uptake of ART. Failure of providers to review history of side effects prevented the development of a good adherence plan with patients in finding strategies to minimize side effects. Failure of providers to discuss latest laboratory tests (including CD4 count) may create difficulties to know when the patient is due for the specific laboratory test and what other tests may be of important for the patient. This may interfere with the correct diagnosis of a patient, which sometimes may worsen the patient's condition and reduce the interest of taking ART. Failure to describe food requirement of patient may subject the patient to take medication without any proper plan of food as recommended for such patients, failure to describe special instruction to patient about medication may put a patient in a position of taking the medicine irregularly which may cause overdosing or under-dosing resulting to worsening the patient's condition leading to interference of daily activities and medication schedule.

Moreover, failure to describe storage issue of medication may cause patients to be ignorant about the storage condition so may keep medicines anyway and causing damage, failure to review medicine interaction with patients may subject patients to medicine related side effects as the patient may combine ARV with other medicine being modern or traditional medicine. Due to side effects patients may withdraw from ART.

According to these findings it show that competence in delivering information during counseling differs among health providers, where inconsistence information about ART were delivered to patients in various health facilities of Mbeya city council. This means the information given to patients also differs, because some received complete package of information while some do not. For that case failure to provide complete package of information to every patient during adherence counseling suggests that counseling provided is not of that quality stipulated in the guideline and may restrain chances of accessing information on ART among patients. The previous study (Gourlay, 2013; Musheke et al. 2012) shows that insufficient number of skilled staff, negative attitude and bad behaviour of providers hindered uptake of ART, but this study has revealed differing competences among service providers in delivering ART information may hinder the uptake. Organization and delivery of the health services reported to affect uptake of ART in previous studies (Tadesse, 2015 and Roula et al, 2009) in which distance to medical services and related travel costs associated with the ART drop out among pregnant women living with HIV, but this was not found in this study. 
Although the current study has demonstrated some unreported views for low uptake of ART, we did not manage to collect sufficient data from LTFU patients due to difficulties in obtaining them. Thus, our results should be interpreted with care and should not be generalized to other areas with similar subjects. Despite the above limitations, the study suggests that individual, social and health service aspects may be playing an important role in lowering uptake of ART among pregnant women in health facilities of Mbeya City.

\section{Conclusion}

This study indicates that various factors at individual, social and health service levels were more likely to cause low uptake of ART. The low uptake of ART may have the negative impact in the Prevention of Mother to Child Transmission of HIV as may decrease the number of pregnant women who use ART for PMTCT in the Region. This study accounts for the need of more strategies to address the low uptake of ART based on individual, social and health services aspects to reduce the burden of HIV transmission.

\section{Acknowledgement}

We wish to acknowledge all in-charges and health care providers worked in PMTCT clinics of Mbeya city council and all pregnant women who participated in this study, without them this study would not have been possible.

\section{Conflicts of Interest}

The authors declare that they have no competing interests

\section{Authors' Contributions}

This manuscript is based on a study conducted in the partial fulfillment of a Masters of Science in Health Monitoring and Evaluation 2017. EM designed the study. LM critically reviewed the study and contributed significantly in the development of the study. EM collected, cleaned and analyzed data. EM \& LM drafted the manuscript. All authors read, revised and approved the final manuscript. We sincerely appreciate the tireless effort from Dr. Debbie Bain Brickley of the University of California, San Francisco for the critical review and guidance in the improvement of this manuscript.

\section{References}

Cataldo, F., Chiwaula, L., Nkhata, M., van Lettow, M., Kasende, F., Rosenberg, R., et al., (2014). Exploring women and health care workers experiences in the context of PMTCT Option B Plus in Malawi. Abstract ICASA

Mbeya city District Health Information System. (2015). Prevention of Mother to Child Transmission Annual report

Hodgson, I., Plummer, M. L., Konopka, S. N., Colvin, C. J., Jonas, E., Albertini, J., \& Fogg, K. P. (2014). A System Review of Individual and Contextual Factors Affecting ART Initiation, Adherence, and Retention for HIV-Infected Pregnant and Postpartum Women

Gourlay, A., Birdthistle, I., Mburu, G., Iorpenda, K., Kerr, A., \& Wringe, A. (2013). Barriers 
and facilitators to the uptake of antiretroviral drugs for prevention of mother to child transmission of HIV in sub-Saharan Africa: a system review.

Kim, M. H., Zhou, A., Mazenga, A., Ahmed, S., Markham, C., \& Zomba, G. et al (2016). Why Did I Stop? Barriers and Facilitators to Uptake and Adherence to ART in Option B+ HIV Care in Lilongwe, Malawi. PLoS ONE 11(2), e0149527. doi:10.1371/journal.pone.0149527

Ministry of Health Community Development Gender, Elderly and Children and National AIDS Control Programme, (2013). National guideline on Prevention of Mother to Child Transmission of HIV

Ministry of Health, Community Development Gender, Elderly and Children. (2013). National Prevention of Mother -to -Child Transmission (PMTCT) of HIV guideline.

Ministry of Health, Community Development Gender, Elderly and Children. (2013). National Prevention of Mother -to -Child Transmission (PMTCT) of HIV Refresher Training guideline Mother Child follow- up report, (2015)。

Musheke, M., Virginia, B., \& Sonja, M. (2012) Individual and contextual factors influencing patient attrition from ART.

NACP, (2011)。 Implementation of HIV/AIDS Care and Treatment Services in Tanzania; Report Number 2

Roura, M. J., Busza, A., Wringe, D., Mbata, M., Urassa, \& Zaba, B. (2009). Barriers to sustain Antiretroviral Treatment in Kisesa, Tanzania: A follow-up study to Understand Attrition from the Antiretroviral ProgramProgramme. AIDS Patient Care STDS, 23(3), 203-10.

Tanzania Country Operational Plan (COP). (2015). Strategic Direction Summary

Tanzania HIV/AIDS and Malaria Indicator Survey (THMIS), (2012).

UNAIDS, (2012). Global report: UNAIDS report on the global AIDS epidemic 2012. Geneva, Switzerland: UNAIDS, WHO.

UNAIDS, (2013). Global report: UNAIDS report on the global AIDS epidemic 2013. Geneva, Switzerland, UNAIDS, WHO.

UNAIDS, (2016). Global AIDS up date.

World Health Organisation, (2013). Consolidated guideline on the use of antiretroviral drugs for treating and preventing HIV infection.

World Health Organisation, (2013). Global update on HIV treatment: results, impact and opportunities.

World Health Organisation, (2015). Guideline on when to start antiretroviral therapy and on pre-exposure prophylaxis for HIV. 


\section{Copyright Disclaimer}

Copyright for this article is retained by the author(s), with first publication rights granted to the journal.

This is an open-access article distributed under the terms and conditions of the Creative Commons Attribution license (http://creativecommons.org/licenses/by/4.0/). 